\title{
Causes of Surgical Delay and Demographic Characteristics in Patients with Hip Fracture*
}

\author{
Sjöstrand Desirée ${ }^{1}$, Hommel Ami ${ }^{1}$, Johansson Anders ${ }^{2 \#}$ \\ ${ }^{1}$ Department of Clinical Sciences, Lund University and Skane University Hospital, Lund, Sweden; ${ }^{2}$ Sections of Anaesthesiology and \\ Intensive Care, Department of Clinical Sciences, Lund University and Skane University Hospital, Lund, Sweden. \\ Email: "anders.johansson@med.lu.se
}

Received June $19^{\text {th }}, 2013$; revised July $15^{\text {th }}, 2013$; accepted July $25^{\text {th }}, 2013$

Copyright (C) 2013 Sjöstrand Desirée et al. This is an open access article distributed under the Creative Commons Attribution License, which permits unrestricted use, distribution, and reproduction in any medium, provided the original work is properly cited.

\begin{abstract}
Background: Several studies analyze how surgical delay affects patients with hip fracture. The aim of this study was to identify the causes of surgical delay and demographic characteristics in patients with hip fracture who had delays longer than 24 hours from admission to hospital. Methods: Quantitative retrospective register study of 484 patients was consecutively included during the period November 1, 2010 and October 31, 2011 in the University Hospital in Lund (Sweden). Results: A frequency of $29.4 \%$ had a surgical delay longer than 24 hours. The main reasons for delays to surgery were lack of theatre facilities (54\%), medical unstable patient (16\%) and anticoagulant treatment (10\%). Of all patients, $69 \%(n=332)$ were women and 31\% $(n=151)$ were men. The mean age for women were $83.6($ CI $83-85)$ vs. 79 (CI 77 - 81) for men, respectively. The most common type of hip fracture was displaced cervical hip fracture $(39 \%, n=188)$ with a majority of fractures in male patients. In total, women suffered hip fractures to a greater extent than men (69\% vs. $31 \%, p=0.016)$, but no relationship was found with respect to the fracture type and age $(p=0.358)$. Conclusion: The main result demonstrated that delays longer than 24 hours were due to lack of theatre facilities. Further researches have to be done in order to investigate whether lack of theatre facilities depends on improper operation planning and/or on lack of medical staff.
\end{abstract}

Keywords: Orthopedics; Hip Fracture; Surgical Delay; Register Study

\section{Introduction}

Hip fracture is one of the conditions that have become a major problem with significant post-fracture disability, reduced quality of life as well as increasing mortality [1]. The number and the proportion of older persons are growing in practically all countries [2]. With the increasing proportion of elderly in the worldwide population, the number of cases of hip fracture will inevitably rise $[3,4]$. It is estimated that the annual number of hip fractures worldwide will rise from 1.7 million in 1990 to around 6.3 million by 2050. Each year in Sweden (with around 9 million inhabitants), approximately 18,000 patients are hospitalized and operated due to hip fractures $[5,6]$.

Despite a growing awareness of the impact on quality of life and on outcome after hip fracture, the surgical

\footnotetext{
*Conflict of interest: We declare there isn't any conflict of interest. Funding: This research needed no funding.

${ }^{\#}$ Corresponding author.
}

delay is still an abundant problem among hip fracture patients [7-11]. Several studies have shown that delayed surgery in patients with hip fracture prolongs hospitalization and increases morbidity, the number of complications, physical and psychological suffering and mortality $[10,12,13]$. However, some recently published studies have suggested that there is a correlation between early surgery and decrease in postoperative complications. Patients with hip fracture who were operated within 24 hours from admission have fewer complications and lowered mortality risk than those patients who had to wait longer for surgery [3,8,9,14,15]. Regardless of this knowledge, some studies indicate that a significant number of patients suffer according surgical delay and some studies point out improper operation planning and/or staff unavailability at the surgical department $[11,16]$. To our knowledge, there are no published trials with the aim of explicitly identifying the causes of surgical delay in patients with hip fracture. 


\section{Material and Methods}

The study was approved by the Ethics Committee of the Medical Faculty of the Lund University (VEN 128-11) and has been performed in accordance with the declaration of Helsinki. Study sample includes entirely 484 patients undergoing surgery for hip fracture during the period November 1, 2010 and October 31, 2011 at Skåne’s University Hospital in Lund (Sweden). Both patients who underwent surgery within 24 hours and patients with surgical delays longer than 24 hours were included. The reason for this was to exactly identify the proportion of individuals who underwent surgery later than 24 hours after admission and to precisely describe the whole group of hip fracture patients during the study period. One patient was excluded from the study and the reason was that the patient passed away before surgery was possible.

All data for the study were collected from the Swedish National Hip Register, RIKSHÖFT. The main purpose of the registry is to ensure continuous quality and to create a high quality of care for hip fracture patients across the country [13]. The registry consists of several forms which are used to collect data about the patient, the treatment, the functional outcome and the rehabilitation outcome. For this study we created a new document with variables from these forms which were considered relevant to the purpose of the study. These variables were: age, gender, fracture type, date of arrival, time of arrival, start time for surgery, surgery within 24 hour and reason for delay. In order to identify if there was any connection between the number of delays and day of arrival we converted the category date of arrival to day of the week of arrival. Afterwards and to determine whether the number of delays was affected by the time of arrival, we divided the day into 4 intervals: 7:00 to $12: 00,12: 01$ to $17: 00,17: 01$ to 9:00 p.m. and 9:01 p.m. to 6:59, respectively. The register was checked by authorized personnel and a further regular check of the collected data was carried out in order to ensure the reliability of the study: the data of every twentieth patient was compared to the original from the Swedish National Hip Register.

\section{Statistics}

Data were analyzed using the Statistical Package for Social Sciences (SPSS 14.0). Results are presented using descriptive statistics according to numbers of patients (n), mean/median, standard deviation (SD) and proportions where appropriate.

A comparative analysis was performed to identify statistical differences between fracture type and gender, fracture type and age, number of delays and day of the week of arrival, delays and time of arrival, delays and age, and between delays and gender. Normal distribution was determined by Kolmogorov-Smirnov test. Compari- son analyses were carried out with confidence interval (CI) for age, Chi-Square test was used for nominal data and for differences of proportions, and Fisher's exact test was used when variables were less than 5 . Ratio data was analyzed with Student's t-test. A statistically significant difference was regarded as $\mathrm{p}<0.05$.

\section{Results}

\subsection{Demographics}

The study group enrolled in the study consisted of 483 hip fracture patients, $69 \%(\mathrm{n}=332)$ were female and $31 \%(n=151)$ were men. Age ranged between 22 and 98 years in men and between 45 and 102 years in women. Mean age for men was 79 (CI 77 - 81) and 83.6 (CI 83 85) for women, respectively. The most common type of hip fracture was the displaced cervical hip fracture (39\%, $\mathrm{n}=188$ ) with a clear majority of fractures in male patients. Overall, women suffer hip fractures to a greater extent than men $(69 \%$ vs. $31 \%, p=0.016)($ Table 1). However, no statistically significant relationship was found with respect to the fracture type and age $(\mathrm{p}=$ 0.358).

\subsection{Surgical Delay and Effect of Age and Gender}

A number 29.4\% $(n=142)$ patients had to wait over 24 hours before surgery with no significant difference between the "24-hour target" and gender $(\mathrm{p}=0.516)$. The patients who were operated in within 24 hours from admission were significant older $(\mathrm{p}=0.022)$ (Table 2).

\subsection{Causes of Surgical Delay}

The most common reason for surgical delay was "lack of theatre facilities" ( $54 \%, \mathrm{n}=76$ ) followed by "medically unstable patient" $(16 \%, \mathrm{n}=22)$ and "patient on anticoagulant therapy” $(10 \%, n=14)$ (Table 3 ).

\subsection{Surgical Delay and Effect of Time of Day and Day of the Week of Admission}

When day of the week of admission was surveyed the largest number of patients arrived at the hospital on Thursday and a minimum number of patients on Sundays with no statistical differences between the number of delays to surgery and the day of the week $(p=0.248$, Table 4). Depict Time of day of admission showed that the majority of patients arrived at the hospital between 12:01 and 17:00 (Table 5), with no differences between the time points $(\mathrm{p}=0.345)$. The largest proportion of patients had to wait between 24 and 48 hours for surgery (Table 6). The mean waiting time for patients with delayed surgery was $40 \pm 29$ hours with a mean median value of 30 hours. 
Table 1. Incidence of fracture types.

\begin{tabular}{|c|c|c|c|c|c|c|c|}
\hline \multirow[t]{2}{*}{ Gender } & \multicolumn{7}{|c|}{ Fracture type } \\
\hline & Cervical & Displaced cervical & Basocervical & $\begin{array}{c}\text { Trochanteric } 2 \\
\text { fragment }\end{array}$ & $\begin{array}{l}\text { Trochanteric } \\
+2 \text { fragment }\end{array}$ & Subtrochanteric & Total (n) \\
\hline Men & $9.9 \%$ & $51 \%$ & $2 \%$ & $13.2 \%$ & $15.9 \%$ & $7.9 \%$ & 151 \\
\hline Women & $12.9 \%$ & $33.6 \%$ & $4.2 \%$ & $19.8 \%$ & $18.9 \%$ & $10.5 \%$ & 332 \\
\hline Total & $12 \%$ & $39 \%$ & $3.5 \%$ & $17.8 \%$ & $18 \%$ & $9.7 \%$ & 483 \\
\hline
\end{tabular}

Analysis between gender and frequency of fractures, $\mathrm{p}=0.016$, Pearson's chi-squared test.

Table 2. Compliance with 24-hour goal.

\begin{tabular}{cc}
\hline Compliance with 24-hour goal & Mean age $( \pm$ SD) \\
\hline Yes & $83 \pm 11$ \\
No & $80 \pm 11$ \\
\hline
\end{tabular}

Difference between "24-hour goal” according to age: $\mathrm{p}=0.022$, T-test.

Table 3. Causes of surgical delay.

\begin{tabular}{ccc}
\hline Cause of delay & Total (n) & Percent (\%) \\
\hline Delayed examination & 1 & $<1$ \\
Repeated X-ray & 1 & $<1$ \\
Diagnosis after CT scan & 5 & 4 \\
Diagnosis after MRI & 3 & 2 \\
Administrative delay & 3 & 2 \\
Lack of theatre facilities & 76 & 54 \\
Surgeon not available & 1 & $<1$ \\
Anesthesiologist not available & 1 & $<1$ \\
Medically unstable patient & 22 & 16 \\
Gastrointestinal haemorrhage & 2 & 1 \\
To determine the diagnosis & 9 & 6 \\
Recent myocardial infarction & 2 & 1 \\
Anticoagulant therapy & 14 & $<1$ \\
Other & 1 & $\mathbf{1 0 1}$ \\
Total & $\mathbf{1 4 2}$ & \\
\hline
\end{tabular}

\section{Discussion}

The purpose of this study was to identify the cause of the delay to surgery in patients with hip fracture in Skåne, southern Sweden. The variables analyzed were considered important for the development and assurance of care for this patient population. In summary, the results showed that the main reason for surgical delay was lack of theatre facilities (54\%) and Medical unstable patient (16\%).

According lack of theatre facilities we could not find
Table 4. Number of delays to surgery and day of the week of admission.

\begin{tabular}{ccc}
\hline Day of the week & Total (n) & Percent (\%) \\
\hline Monday & 74 & 15.3 \\
Tuesday & 73 & 15.1 \\
Wednesday & 77 & 15.9 \\
Thursday & 81 & 16.9 \\
Friday & 63 & 13.0 \\
Saturday & 65 & 13.4 \\
Sunday & 50 & 10.3 \\
Total & 483 & 100 \\
\hline
\end{tabular}

$\mathrm{p}=0.248$, Pearson's chi-squared test.

Table 5. Time of day of admission.

\begin{tabular}{cccc}
\hline Time & Total (n) & Percent (\%) & Number delays \\
\hline 7:00 to 12:00 & 101 & 20.9 & 30 \\
12:01 to 17:00 & 172 & 35.5 & 59 \\
17:01 to 21:00 & 99 & 20.7 & 28 \\
21:01 to 06:59 & 111 & 22.9 & 25 \\
Total & 483 & 100 & 142 \\
\hline
\end{tabular}

$\mathrm{p}=0.345$, Pearson's chi-squared test.

Table 6. Number of patients within the different time points that underwent surgery later than 24 hours from admission.

\begin{tabular}{cccccccc}
\hline Hours to surgery & Mon & Tu & Wen & Thur & Fri & Sat & Sun \\
\hline $\mathbf{2 4}$ - $\mathbf{4 8}$ hours & 14 & 17 & 25 & 23 & 14 & 20 & 8 \\
$\mathbf{4 8}-\mathbf{7 2}$ hours & 3 & 3 & 1 & 2 & 2 & 1 & 0 \\
More than $\mathbf{7 2} \mathbf{h}$ & 2 & 2 & 0 & 1 & 4 & 0 & 0 \\
Total & $\mathbf{1 9}$ & $\mathbf{2 2}$ & $\mathbf{2 6}$ & $\mathbf{2 6}$ & $\mathbf{2 0}$ & $\mathbf{2 1}$ & $\mathbf{8}$ \\
\hline
\end{tabular}

$\mathrm{p}=0.248$, Fisher's exact test.

information why the absence occurred. A probable reason could be improper operation planning or staff unavailability in the surgical department, since these are known issues [11]. Similar results emerged in an Aus- 
tralian study by Hamish et al. [16] where $58 \%$ of the delays were due to lack of theater facilities and 33\% due to medical unstable patient. Hommel et al. [9] describes comparable findings in Sweden.

In present study, there was a significant difference in age between men and women (men 79 vs. women 84). The fact that women suffer more frequently than men of hip fractures and that affected women are older than men agrees well with the national register [17] and with other studies $[3,15,18]$. Several published studies on this topic show similar distribution of gender $[3,9,15,18]$. The overwhelming proportion of women who are usually seen in the majority of the studies can be explained by two reasons: the fact that women have a higher life expectancy and that women have an increased tendency to osteoporosis [2]. Most of the studies in which the topic hip fracture is surveyed exclude patients over 60 - 65 years. In our study, no patients were excluded because of age.

According to the National Board of Health and Welfare guidelines for the care and treatment of patients with hip fractures the most common fracture type is the displaced cervical fracture [19]. Our analysis showed similar results. However, we found that women suffered more than men of this particular fracture $(59.5 \%$ vs. $40.5 \%$ ) as women were more disposed to hip fractures. This fact is confirmed by RIKSHÖFT annual reports. When the reports for the past six years were analyzed $[17,20-24]$, it demonstrated that the fracture types followed the same pattern as in our study and that the distribution for fracture type was similar for both sexes. This outcome is confirmed by Gjersten et al. [4], in their study $72 \%$ of the participants were women and $38.1 \%$ of all fractures were classified as displaced cervical fractures. In terms of frequency distributions of gender, age and fracture type, our study is comparable with other studies concerning the subject.

Regarding the relationship between late surgery (not within 24-hour) and gender we found no significant difference. This is in contrast with Novack et al. [3] study in which the proportion of males not operated was higher than that of female patients $(21.8 \%$ vs. $16.1 \%$, respectively). Additionally, they found no differences according to age whether our analysis revealed a significant correlation between to "surgery within 24 hours". Patients who met the "24-hour target" after arrival to the hospital were older than the group of patients with delayed surgery.

Regarding the fulfillment of the "24-hour target", our result showed that surgery was started within 24 hours in $70.6 \%$ of the cases. This figure corresponds well with the figures of the regions Center for Operational Planning and Analysis [25]. However, international surgical delays are often defined in different ways and make it more difficult to compare and evaluate our results. In the study by Novack et al. [3] the authors reported only the number of patients who underwent surgery within 48 hours from arrival to the hospital.Of the included 4633 patients, there were $17.6 \%$ who did not undergo surgery and $29.1 \%$ who underwent surgery within 48 hours. These proportions corresponds to a Spanish study by Librero et al. [15] that demonstrated an amounts of $24.7 \%$ of patients were receiving surgery within the first days after arrival to the hospital.

The OECD health report analyzed how health care quality indicators have been between 1999 and 2004 in OECD countries [26]. When time to surgery in hip fracture patients was surveyed this issue demonstrated significant differences between countries. The proportions of patients who underwent surgery within 48 hours of arrival at the hospital were as follows: Sweden 93.5\%, Norway 93\%, Finland 86\%, Netherlands 80.4\%, Canada 79.5\%, Iceland 73.1\%, Denmark 68.1\%, Mexico 65.1\%, UK $61.5 \%$, Italy $32.7 \%$ and Portugal $50.1 \%$. It is clear that there are considerable differences between the various countries in the world in terms of quality indicators for patients with hip fracture.

When we analyzed Day of the week and Time of arrival, no correlation could be confirmed. Correspondingly, Novack et al. [3] demonstrated that there was no difference in surgical delay depending on which day of the week the patients arrived at the hospital. According to our result the largest proportion of patients who had delayed surgery waited between 24 and 48 hours before surgery. These findings agree well to the results of other studies [15,27].

We believe that there is some strength with present study. Before the start of the study and with regard to the study purpose, appropriate data collections were discussed with coordinator of the Swedish National Hip Registry. We enrolled all patients from one year in an effort to minimize the risk of bias that could influence of differences in staffing, due to decreased production during summer and national holidays. We also believe that the study is based on a sufficiently large sample where the drop out is minimal and therefore we consider the results reliable.

Even if there have been significant improvements to streamline the management of hip fracture patients, the hospital of Lund has not been able to meet Region Skåne's goal (surgery within 24 hours from admission into hospital for at least $80 \%$ of all patients with hip fracture) during the period, though only $70.6 \%$ of the patients had surgery within the first day. If the main reason for the result was due to improper planning at the surgical department or due to understaffing had to be investigated. Although it has been difficult to find studies within the subject (e.g. cause of delay to surgery), we 
believe that our study could contribute to future actions and measurements, in order to further optimize the health care program for these patients and a prospective study might be useful in order to better identify the causes of the surgical delay.

\section{Conclusion}

The causes of delay to surgery within 24 hours occurred in $29.4 \%$ of all patients with hip fracture. The main reasons for delays were lack of theatre facilities (54\%), medical unstable patient (16\%) and anticoagulant treatment (10\%). The most common type of hip fracture was displaced cervical hip fracture (39\%) with a majority of fractures in male patients.

\section{REFERENCES}

[1] A. Hommel, "Improved Safety and Quality of Care for Patients with a Hip Fracture,” Ph.D. Dissertation, Lunds Universitet, Institutionen för Hälsa, Vård Och Samhälle, 2007.

[2] WHO, "Sweden: “Nutrition for Older Persons,” 2011. www.who.int/nutrition/topics/ageing/en/index2.html

[3] V. Novack, A. Jotkowitz, O. Etzion and A. Porath, "Does Delay in Surgery after Hip Fracture Lead to Worse Outcomes? A Multicenter Survey," International Journal for Quality in Health Care, Vol. 19, No. 3, 2007, pp. 170-176. doi:10.1093/intqhc/mzm003

[4] J.-E. Gjertsen, L.-B. Engesæter, O. Furnes, L.-I. Havelin, K. Steindal, T. Vinje and J.-M. Fevang, "The Norwegian Hip Fracture Register Experiences after the First 2 Years and 15,576 Reported Operations," Acta Orthopaedia, Vol. 79, No. 5, 2008, pp. 583-583. doi:10.1080/17453670810016588

[5] National Board of Health and Welfare, "Sweden: Fallskador i Vården,” 2011.

http://www.socialstyrelsen.se/patientsakerhet/riskomrade $\mathrm{n} /$ fallskador

[6] RIKSHÖFT, “Sweden: Höftfrakturer; 2009a,” 2009. http://www.rikshoft.se/se/index.php?option=com_content \&view $=$ article\&id $=50$ \&Itemid $=37$

[7] J. Richmond, G.-B. Aharonoff, J.-D. Zuckerman and K.-J. Koval, "Mortality Risk after Hip Fracture," Journal of Orthopaedic Trauma, Vol. 17, No. 1, 2003, pp. 53-56. doi:10.1097/00005131-200301000-00008

[8] P. Vestergaard, L. Rejnmark and L. Mosekilde, "Increased Mortality in Patients with a Hip Fracture-Effect of PreMorbid Conditions and Post-Fracture Complications," Osteoporosi International, Vol. 18, No. 12, 2007, pp. 1583-1593. doi:10.1007/s00198-007-0403-3

[9] A. Hommel, K. Ulander, K. B. Björkelund, P.-O. Norman, H. Wingstrand and K.-G. Thorngren, "Influence of Optimised Treatment of People with Hipfracture on Time to Operation, Length of Hospital Stay, Reoperations and Mortality within 1 Year," International Journal of the Care of the Injured, Vol. 39, No. 10, 2008, pp. 1164-1174. doi:10.1016/j.injury.2008.01.048
[10] S.-K. Khan, S. Kalra, M. M. Thiruvengada and M. J. Parker, "Timing to Surgery for Hip Fractures: A Systematic Rewiew of 52 Published Studies Involving 291,413 Patients," International Journal of the Care of the Injured, Vol. 40, No. 7, 2009, pp. 692-697. doi:10.1016/j.injury.2009.01.010

[11] N. Simunovic, P. J. Devereaux and M. Bhandari, "Surgery for Hip Fractures: Does Surgical Delay Affect Outcomes?” Indian Journal Orthopaedia, Vol. 45, No. 1, 2011, pp. 27-32. doi:10.4103/0019-5413.73660

[12] K. B. Björkelund, “Acute Confusional State in Elderly Patients with Hip Fracture. Identification of Risk factors and Intervention Using a Prehospital and Perioperative Management Program,” Ph.D. Dissertation, Lunds Universitet, Institutionen för Hälsa, Vård Och Samhälle, 2008.

[13] RIKSHÖFT, “Sweden: Om Rikshöft; 2009b,” 2011. http://www.rikshoft.se/se/index.php?option=com_content \&view $=$ article\&id $=46 \&$ Itemid $=27$

[14] A. Bottle and P. Aylin, "Mortality Associates with Delay in Operation after Hip Fracture: Observational Study," British Medical Journal, Vol. 332, No. 7547, 2006, pp. 947-951. doi:10.1136/bmj.38790.468519.55

[15] J. Librero, S. Peiró, E. Leutscher, J. Merlo, E. BernalDelgado, M. Ridao, N. Martínez-Lizaga and G. SanfélixGimeno, "Timing of Surgery for Hip Fracture and In-Hospital Mortality: A Retrospective Population-Based Cohort Study in the Spanish National Health System,” BMC Health Services Research, Vol. 12, No. 15, 2012. doi:10.1186/1472-6963-12-15

[16] C. R. Hamish, I. A. Harris, L. Mcevoy and T. Todovora, "Delay to Surgery and Mortality after Hip Fracture," The Australian and New Zealand Journal of Surgery, Vol. 77, No. 10, 2007, pp. 889-891. doi:10.1111/j.1445-2197.2007.04267.x

[17] RIKSHÖFT-SAHFE, “Annual Report 2009,” 2012. http://rikshoft.se/se/images/stories/arsrapporter/arsrapport 2009.pdf

[18] K. B. Björkelund, A. Hommel, K.-G. Thorgren, L. Gustafson, S. Larsson and D. Lundberg, "Reducing Delirium in Elderly Patients with Hip Fracture: A Multi-Factorial Intervention Study," Acta Anaesthesiologica Scandinavia, Vol. 54, No. 6, 2010, pp. 678-688. doi:10.1111/j.1399-6576.2010.02232.x

[19] National Board of Health and Welfare, "Guidelines for Care and Treatment in Patients with Hip Fracture,” Socialstyrelsen, Stockholm, 2003.

[20] RIKSHÖFT-SAHFE, “Annual Report 2005,” 2011. http://rikshoft.se/se/images/stories/arsrapporter/Arsrappor t2005.pdf

[21] RIKSHÖFT-SAHFE, “Annual Report 2006,” 2011. http://rikshoft.se/se/images/stories/arsrapporter/Arsrappor t2006.pdf

[22] RIKSHÖFT-SAHFE, “Annual Report 2007,” 2011. http://rikshoft.se/se/images/stories/arsrapporter/Arsrappor t2007.pdf

[23] RIKSHÖFT-SAHFE, “Annual Report 2008,” 2011. http://www.rikshoft.se/se/images/stories/arsrapporter/Arsr apport2008.pdf 
[24] RIKSHÖFT-SAHFE, “Annual Report 2010,” 2012. http://rikshoft.se/se/images/stories/arsrapporter/arsrapport 2010.pdf

[25] Center for Operational Planning and Analysis, 2011. http://www.skane.se/Upload/Webbplatser/vardgaranti/l\% C3\%A4gesbilder/Uppf\%C3\%B6jlning\%20T2\%202011\% 20h\%C3\%B6ftprocessm\%C3\%A5l\%20internetversion\% 20_3_.pdf
[26] HCQI, “Health Care Quality Indicators Project. Initial Indicators Report,” 2012.

http://www.oecd.org/dataoecd/1/34/36262514.pdf

[27] M. P. Fantini, G. Fabbria, M. Lausb, E. Carrettaa, S. Mimmia, G. Franchino, L. Faveroc and P. Rucci, "Determinants of Surgical Delay for Hip Fracture,” The Surgeon, Vol. 9, No. 3, 2011, pp. 130-134. doi:10.1016/j.surge.2010.11.031 